\title{
Las cualidades que debe tener el hombre de leyes(1)
}

\author{
por el Dr. LUIS ECHECOPAR GARCIA, \\ Catedrático Titular de Derecho Civil \\ en la Universidad Católica del Perú.
}

Me toca hablar ante vosotros en esta jornada de estudios $y$ debo confesar que mi preocupación es grande.

Hasta ahora he sido profesor universitario $y$, por consiguiente, sólo he enseñado a jóvenes estudiantes, respecto de quienes tenía doble ventaja: de un lado, el poder ofrecerles algo nuevo, desde que ellos recién se estaban iniciando en los conocimientos del curso respectivo; $\mathrm{y}$, de otro, mis estudios universitarios y mi experiencia de algunos años de ejercicio de las abogacía.

En cambio hoy la situación es completamente diferente pues me co. rresponde actuar como ponente ante una asamblea de juristas; prácticamente enseñar a los que ya saben, señalar reglas de conducta $\alpha$ quienes las conocen y practican en grado eminente; $y$ emplear para ello mis reducidos medios ante personas de elevada cultura jurídica, con experiencia $Y$ estudios seguramente análogos o superiores $\alpha$ los míos.

Quien sabe podreís preguntaros por qué intervengo entonces, cuál es el objeto de mis palabras, y por qué me atrevo a decirlas, y debo contesiar que procedo en este caso prácticamente como un soldado.

He sido movilizado dentro de las Jornadas Eucarísticas $\mathrm{y}$ hé pensado que debía obedecer al mandato, en la convicción de que muchas veces el Todopoderoso se vale de modestos elementos para poner en marcha sus grandes fines.

No oculto que también me ha seducido para hablar ante vosotros mi: entrañable amor a nuestra profesión y el vivo deseo que el mismo me inspira de examinar sus problemas.

El tema de mi ponencia es el segundo: las cualidades que debe tener el hombre de leyes, catedrático, magistrado o abogado, y al plantearlo he de deciros que me encuentro con una nueva dificultad.

De un lado podría haceros rápidamente la lista de las cualidades:

(1) Discurso pronunciado, en el Colegio de Abogados de Lima, con motivo de la Semanar de Estudios del Ve Congreso Eucarístico Nacional y Mariano de Lima. (1954). 
que debe tener el jurista y terminar allí en pocas palabras. Podría deciros. que el catedrático de derecho ha de tener una sólida formación moral, intelectual y cultural; ser estudioso y cumplido; fiel a la verdad en el pensamiento, en la investigación y en la palabra; listo a sacrificarse por los estudiantes, por el bien y por la ciencia; claro y profundo en su exposición; respetuoso del pensamiento ajeno $y$ tolerante con los errores de sus alumnos, pero firme en la disciplina e inflexible con el mal y con la mentira.

Podría expresar también que el magistrado debe participar de estas cualidades, en cuantó le son aplicables, tener un gran respeto hacia el orden jurídico positivo al mismo tiempo que por la ley moral, ser dedicado al trabajo, imparcial e incorruptible y no tener más mira en sus fallos que la justicia.

Podría enumerar, en fin, los atributos que deben adornar a todo abogado $y$ las obligaciones de todo profesional como son: mantener la continuidad de sus servicios; respetar las leyes y las autoridades públicas; tener justa consideración hacia los magistrados $y$ exigirla de ellos; actuar con dignidad y moderación en el ejercicio de su función $y$ en la vida privada, observar la más rigurosa probidad o sea incuestionable lealtad, veracidad y buena fé; observar el secreto profesional; ser desinteresado; y proceder con independencia, resguardando celosamente su libertad en la defensa y en toda actividad profesional.

Mas, temo mucho que insistir en todo ésto no sería sino tratar del pan de cada día; y prácticamente repetir lo que dice cualquier reglamento profesional.

En cambio existe otra posibilidad, pero mucho más espinosa: la de referirme al especto trascendente de la vida y ubicar dentro de ella a nuestra profesión. Os pido excusas si con mi reducido bagaje personal me lanzo por este camino; pero creo en realidad que la concepción del hombre de leyes va más allá de lo que puedan señalar enumeraciones y reglamentos y que debemos tratar de ella con un criterio universal; mirando a la eternidad.

Concibo, en efecto, ante todo al jurista como un hombre, como un hijo del Señor, $y$ por lo tanto como un elemento de su orden universal, de ese orden maravillosó de que nos hablaba San Agustín (1), que lo comprende todo, por el que se hacen y mueven las cosas y que nos eleva a Dios.

Dentro de ese orden existen la energía en sus diversas formas, las cosas inanimadas, los seres animados $y$, en fin, el hombre.

Todos se vinculan $\mathrm{y}$ mueven dentro del providencialismo divino; $\mathrm{y}$ por virtud del mismo, el hombre goza de la razón que le permite apreciar las cosas, los actos propios y los ajenos y juzgar sobre ellos; y está dotado del libre albedrío, ésto es de la facultad que le permite actuar según su voluntad, abstenerse $u$ obrar y elegir en cada caso su propio camino; pero razón y libre albedrío le permiten támbién saber que ha sido creado

(1) Obras de San Agustín. Tomo I. Ed. Biblioteca de Autores Cristianos. Editorial Católica.. Madrid 1946, p. 641 y siguientes. 
para mayor gloria de Dios y que es en vista de ella que le corresponde orientar sus actos.

Entendida así la posición del hombre $\mathrm{y}$, por consiguiente, la del jurista, se comprenderá en cuanto se eleva $y$ se dignifica. ¡Qué majestad adquiere la palabra del catedrático, qué inmenso peso tiene la sentencia del juez, qué fuerza tan poderosa impulsa la defensa del abogado o qué equilibrio y ponderación adquiere su actuación cuando sabe que está contribuyendo a la obra del Creador, a su mayor gloria, y que, por lo mismo no puede fallar su misión! ¡En cuánto se rebaja en cambio quien falta $\alpha$ ella!

Toca al jurista, en la tierra, dentro del orden universal, enseñar el derecho, aplicar la ley, ésto es, discernir la justicia o colaborar a la aplicación de la misma.

Pero, cuál es esa ley o derecho que ha de enseñar o aplicar? ¿Solamente la ley positiva, la costumbre, la doctrina o el derecho emanado de la jurisprudencia?

$¿ \mathrm{O}$, es que existen también otras leyes que interesan $y$ deben prea cupar al hombre de leyes?

Creyendo como creemos que existe Dios, porque así nos lo demuestro la razón, porque el universo es un hecho viviente, porque en él hay movimiento $y$ orden, porque el hombre es inteligente $y$ libre, porque en esencia no pueden existir estos efectos sin una causa eterna $y$ perfecta que los origine, porque lo confirma la creencia común del género humano, porqué lo comprueba la experiencia histórica y porque todo demuestra la necesidad indispensable de un ser eterno e inmutable (2) hemos de creer también en la existencia de una ley divina que regula todas estas cosas Y por la cual el Creador establece formalmente las obligaciones de la criatura racional (3), señalóndole el sendero de su conducta moral.

Conocemos está ley por la revelación y podemos llegar a ella, dentro de ciertos límites por la reflexión. Su expresión positiva la constituyen los Mandamientos, nos ilustran sobre la misma los Evangelios. Nas obliga a todos $\mathrm{y}$ debemos cumplirla $\mathrm{Y}$, por consiguiente, no puede prescindir de ella el hombre de leyes.

Pero nos preguntamos si, derivada de esta ley suprema, no existe así mismo una ley escrita en nosotros, la ley - como dice Justiniano- de la Providencia de Dios, la ley natural fuera de la cual no habría racionalidad dentro del complejo de la vida civil (4), ley -también- que por lo mismo debe preocupar hondamente a los juristas; $y$ debemos responder resueltamente que sí.

No puedo, sin embargo, emitir juicio terminante, sin hacer una explicación por cuanto la existencia misma, los fundamentos, la interpreta-

(2) José Salsmans. Deontología Jurídica. Ed. El Mensajero del Corazón de Jesús, Bilbao 1947. p. 17 y sigufentse.

(3) P. A. Hillaire. Ix Religión Demostrada. Ed. Luis Gili, Barcelona, 1930, p. 4 y siguientes.

(4) Domenico Barbero. Revalorización del Derecho Natural. Revista "Criterio" Buenos Aires, No 1180, p. 49. 
ción y la validez próctica del Derecho Natural han sido materia de innumerables objeciones.

Así, para el Panteísmo, no habría un Dios personal distinto del mundo (5). Dios sería el conjunto de seres que forman el universo. No habría. pues, un derecho emanado del Orden Divino sino simplemente de la humanidad.

Para el historicismo (Hugo, Savigny, Puchta, etc.) es tan sólo la Nación que forja las leyes a través de los tiempos, como producto de su. espíritu, vida y cultura, sin que pueda aceptarse un principio superior al hecho histórico y social que sirva como principio de inspiración o de reforma.

Para el individualista, como Rousseau, el hombre, en estado de naturaleza, habría convenido, tácitamente, por su propia voluntad en organizarse en sociedad, dando asi origen a una voluntad común de la cual emanan las leyes.

Para el subjetivista, como Kant, la voluntad está encadenada al deber; la única cosa buena en sí misma es la "buena voluntad" o sea la que quiere algo por respeto al deber (6); y de ello deriva su norma de conducta para cada individuo aislado, su imperativo categórico que dice: "Obra de modo que la móxima a que obedece tu conducta pueda elevarse a principio de legislación universal" (7).

De la aplicación de esta regla a los hombres que actúan en sociedad nace su definición del derecho, como "el conjunto de condiciones por las que el arbitrio de los unos puede coexistir con el arbitrio de los otros, bajo una ley universal de libertad" (8).

Para los positivistas no podemos remontamos más allá de lo que dominan nuestros sentidos, de la ley emanada del Estado.

Piensan que si aceptáramos un derecho natural, válido para todas las relaciones humanas, cortaríamos la vida al derecho positivo y lo haríamos innecesario o imposible.

Según ellos el derecho natural no tiene precisión ni fuerza obligatoria, de modo que la autoridad sólo puede aplicar el derecho positivo $y$. no el natural.

Para los racionalistas, en fin, Ia naturaleza es un concepto abstracto, puesto que se refiere a un conjunto de cosas y fenómenos, pero la naturaleza no da normas ni las garantiza y más bien la norma sale de la inteligencia humana asociada que la garantiza $y$ quiere, siendo el Esta. do el que asegura su aplicación.

No voy a pretender refutar todas estas teorías una por una dentro del breve tiempo con que contamos; por eso basta decir que para aprecior el derecho no podemos detenernos solamente en el concepto de "la:

(5) Hillaire. Ob. Cit. p. 22.

(6) Georges Renard. Introducción Filosótica al Estudio del Derecho. Traducción de Santos: Cuchillos Manterola. Ed. Desclée de Brouwer, Buenos Aires, 1947, T. III. P. 78.

(7) Julián Marías. Historia de la Filosofía. Ed. Manuales de la Revista de Occidente. Madrid 1952, p. 271.

(8) Icilio Vani. Filosofía del Derecho. Traducción de Juan Bautista de Lavalle Y A. M. Cáceres Olazo. Ed. Francesa Y Científica, Casa Editorial E. Rosay. Iima, 1923, p. 391. 
humanidad" ○ de "un pueblo", o de la evolución histórica, 0 del individuo, - de su buena voluntad, o de su razón personal o asociada a la de los: demás, cuando sabemos que hay algo más que todo eso, algo muy superior, que es Dios, que $E l$ ha creado un orden y que ese orden está sujeto. a leyes.

Podría observarse, quien sabe, que cuanto digo se basa en simples afirmaciones dogmáticas, pero no es así.

Desde muy antiguo la razón humana ha reconocido la existencia del Derecho Natural. Diversas interpretaciones se ha dado del mismo pero. todas ellas contienen una verdad esencial: la existencia de una ley anterior y superior a la del hombre y a la que éste no debe sustraerse.

Siete siglos antes de Nuestro Señor, ya la escuela jónica había interpretado la naturaleza "como un orden universal que se impone al mundo moral y a la sociedad asegurando así la autoridad pública" (9).

Sófocles hace hoy cerca de 2400 años nos daba una bellísima expresión al respecto en Antígona, una de sus más conmovedoras tragedias.

Allí la heroína da piadosa sepultura a su hermano Polinicio, hijo de Edipo, a pesar de la prohibición de Creón, cruel y cínico tirano de Tebas. y cuando éste la cpndena a muerte por haber violado sus inhumanas leyes, ella se le enfrenta y aunque confiesa que como mujer que es, su. corazón está hecho para el amor y no para el odio, le dice:

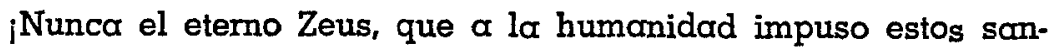
tos ritos, ordenó leyes tales, ni la justicia reinó entre los poderes infernales!

¡No puedo atribuir a tu edicto el poder de infringir las leyes no escritas de los dioses justos, siendo como eres un débil mortal!

¡No son estas leyes de ayer! ¡Viven! ¡Son de siempre! y nadie. puede saber $\alpha$ que pasado remontan.

¡No me atrevería, ni aún atemorizada por amenaza de muerte a violar su sanción e incurrir en la venganza de los dioses!

Aristóteles en su Etica a Nicomaco enuncia la existencia de un derecho natural $y$ de un derecho legal.

Entre los romanos, Cicerón en su República "celebra a cierta ley "que eleva por encima de lás demás leyes... ley por excelencia, la única "que merece el nombre de tal, porque las otras leyes no lo reciben sino por "participación en la... ley verdadera, recta razón, congruente con la natu"raleza, difundida entre los hombres, constante, sempiterna" (10).

San Agustín en el Siglo IV nos describe con sublime elevación el orden natural a que se sujeta el Universo y nos explica como los imperativos de la ley divina constituyen la ley natural.

Santo Tomás de Aquino en el siglo XIII nos indica como el universo

(9) Claude du Pasquier. Introducción a la Teoría General del Derecho y a la Ciencia Jurídica. Traducción de Juan Bautista de Lavalle y Julio Ayasta González. Ed. Iibrería: e Imprenta Gil, Lima, 1944 p. 252.

(10) Georges Renard. Ob. cit. en la nota 6, p. 40. 
está gobernado por la ley eterna basada en la razón divina, y como el hombre estó sujeto a la ley natural reflejo de la razón divina, correspondiendo a la ley humana aplicar los principios de la ley natural a las circunstancias particulares de las diversas sociedades (11).

En 1625 Hugo Grocio estudia profundamente el Derecho natural pero colocando al hombre en el centro de su teoría con una naturaleza sociable $\mathrm{y}$ racional sujeto a preceptos tan inmutables que no podrían ser cambiados ni por Dios mismo. Es Dios quien al crear la naturaleza ha querido que tales principios existan en nosotros; pero éstos aparecen a través de la naturaleza humana y no resultan de la revelación divina (12).

Se inicia con él la época de un "derecho natural" que se aleja de Dios para concentrarse en el hombre, en la naturaleza y que más tarde llega $\alpha$ evolucionar al historicismo con fuerza tal que Gierke en 1883 podía decir:

"Lo que los golpes de la espada de la escuela histórica han dejado subsistir del derecho natural no es mós que una sombra de su antiguo y orgulloso poder" (13).

Pero como sucede en toda forma del pensamiento humano, si el derecho natural ha tenido sus detractores $\mathrm{y}$ ha sido materia de errores, la realidad es que su existencia hoy más que nunca se comprueba en los tratados de los mós notables juristas.

Allí están las obras de Albert Valensín, de Dom Nicolós Perrier, de Guisan, de Giorgio del Vecchio, de Francesco Camelutti, de Guiseppe Capograssi, de Hugo Nicolini, de Monseñor Jacques Leclerq, de Johannes Messner, de E. Brunner, de Enrique Rommen, de Jacques Maritain, del R. P. Fridolin Utz, de C. Luño Peña, de L. Mendizabal y Mortín, de Joaquín Ruiz Jiménez, de Jean Brethe de Ia Gressaye, de Marcel Laborde-Lacoste, de León Juliot de la Morandiere y de tantos otros que cita el profesor Andrés Ruszkowski en su obra de la materia (14).

Podría sostenerse que éstas son meras teorías y que a ellas se oponen otras de singular fuerza, pero debemos responder que no puede dudarse de que existe la naturaleza humana, que el hombre en si mismo, por su organización espiritual, anatómica y fisiológica y por la forma como vive en sociedad en el mundo está sujeto a ciertas reglas que le son inherentes y que son las que mejor convienen $\alpha$ su existencia, a sus necesidades como ser viviente $\mathrm{y}$ a su posterior destino.

La misma tendencia mundial a unificar el Derecho Positivo y la intensificación del derecho comparado nos demuestran la existencia de algo esencialmente común a la humanidad que aún cuando no revista siempre las formas positivas está realmente detrás de toda ley humana que sea adecuada a la naturaleza.

(11) Du Pasquier. Ob. cit. en la nota 9, p. 258.

(12) Id. p. 265.

(13) Andrés Ruszkowrki. Algunas Conquistas de Derecho Natural en la Literatura Juridica Moderna. Separata de la Revista "Derecho", Iina, 1953.

(14) Ruszkowski. Ob. cit. en la nota 13. 
Toda la cuestión reside en saber si esas leyes las posee la humanidad por sí o si le vienen de Dios y nuevamente debo decir que no hay duda que le vienen de Dios.

Nos lo dice la fé, nos lo indica la revelación, pero también nos lo impone la razón, pues bien sabemos que no existe efecto sin causa y que si en el mundo existē algo y si hay un orden cualquiera sólo puede ser en virtud de una causa que lo origine.

Determinado, de este modo, que existe un derecho natural, ésto es un complejo de normas de la vida civil que guían al hombre dentro del orden universal y fuera de las cuales no habría racionalidad (15), que conocemos en parte por nuestra fé, en parte por la revelación y en parte por la razón; nos toca ahora determinar cuál es la naturaleza exacta de las mismas.

Alguien se ha preguntado ¿cuál es el contenido de ese derecho natural, de cuántos artículos consta y cuáles son ellos?, y nosotros tendríamos que contestar: que conocemos los mandamientos, que tenemos los Evangelios y que sabemos que el hombre fué creado a imagen $Y$ semejanza de Dios, con su propia personalidad, distinia de las demás, con libertad para discernir y por lo mismo con una elevada dignidad.

Es un hecho que el hombre existe $\mathrm{y}$ por lo mismo requiere lo indispensable para subsistir.

Corolario de su racionalidad, voluntad y libertad, es su derecho de vivir intelectual, moral y religiosamente.

De sus facultades genésicas y afectivas $\mathrm{y}$ de su sociabilidad deriva su derecho de formar un hogar, de tener descendencia.

De la forma como viene al mundo se desprende el derecho y obligación de los padres de alimentar y educar a los hijos.

De su vida en sociedad, de la existencia de otros hombres con iguales derechos y de las diversas contingencias que trae la vida y la naturaleza, emana la obligación de observar mutuo respeto entre los hombres y la necésidad de que exista una autoridad que vele por el bien común.

Los principios del derecho natural son pues normas-guías que el hombre descubre poco a poco dentro del orden del Universo $y$ que lo conducen a su fin ulterior.

Por lo mismo que tienen este carácter el hombre puede ignorarlas - burlarlas, pero también con ello queda sujeto a lo que Renard ha llamado "el desquite de la naturaleza" (16) a las reacciones que su violación origina," pues no en vano existen esas reglas, ni puede prescindirse de ellas en forma indefinida.

De su carácter también resulta que son progresivas en el sentido de que el hombre a medida que adelante su cultura las va conociendo mejor; como en el caso del físico que antes hacía sus investigaciones con una lupa, más tarde con un microscopio simple y hoy con un microscopio electrónico. Las leyes'de la naturaleza no han cambiado pero hoy el cien-

(15) D. Babero. Artículo citado en la nota 4, N9 1180 p. 48.

(16) Renard. Ob. cit. en Ia nota 6, p. 48. 
tífico puede apreciarlas mejor y casi podría decirse que ésto le permite conocer "otra naturaleza".

Así ocurre con el derecho natural y los errores que se produzcan en su apreciación no significan que no existe, sino, simplemente, que el hombre no es perfecto y que está sujeto al progreso de su mente y de sus conocimientos.

Quien sabe se preguntarớn en este momento quienes me escuchan ¿qué tiene que hacer toda esta disertación sobre el Derecho Natural con el tema de la ponencia, con las cualidades que debe tener el hombre de leyes? y debo recordar que estamos ubicando al jurista dentro de su posición universal y que si por su profesión debe hacer uso de las leyes, por lo menos tenemos que saber qué leyes son éstas para explicar después como debe aplicarlas.

Habiendo establecido que existen leyes divinas, leyes naturales $y$ leyes positivas, (estas últimas las leyes del hombre) nos toca ahora determinar cual es la situación del jurista ante ellas.

Desde luego la posición más sencilla es decir que, en principio, el jurista católico debe obedecer estrictamente las leyes y ordenamientos legítimos de la autoridad civil, aún cuando no apruebe los principios políticos, las intenciones, ni los actos de los gobemantes, por cuanto toda autoridad legítima viene de Dios, sea directamente al gobernante, sea al pueblo para que éste la confíe al gobemante, ya que, siendo todos los hombres iguales y libres, ni la voluntad de uno sólo, ni la voluntad de la mayoría, serían razón suficiente para subordinarlo a los demás. Repugnaría en realidad a la dignidad humana inclinarse ante los otros, si no reconociéramos que el Estado actúa dentro del Orden Universal y que dentro de ese orden está que alguien ejerza la autoridad para el bien general $\mathrm{y}$, como un refiejo de la autoridad del Creador.

Mientras el derecho positivo sea justo, bien aplicado y debidamente cumplido, no hay así problema alguno, pero la cuestión se complica grandemente, cuando el estado abusa o tiende a abusar de su poder, en cualquiera de sus ramas; cuando la ley es moralmente injusta; cuando el que debe cumplirla procura evadirla sea por falta de sentido moral, sea porque desconfía de ella.

Surge entonces la importancia de conocer que vivimos dentro de un orden providencial; que existen leyes divinas y un derecho natural irrenunciable, como atributo que Dios ha dado a la humanidad.

¿En virtud de qué, en efecto, puede el hombre impedir al Estado que por decisión de la mayoría dicte leyes tiránicas para ejecutarlas tiránicamente? ¿Qué razón puede limitar las facultades de un congreso soberano e impedirle dictar leyes bárbaras que, por ejemplo condenen a toda una raza a la incineración en el horno crematorio o a la esterilización por la simple razón de su origen? ¿Qué ley puede detener al poderoso cuando desea abusar del hombre, reducirlo a la esclovitud, usarlo como conejillo para sus experimentos? ¿Qué ley puede impedir $\alpha$ un Estado omnipotente avasallar a sus vecinos inermes? ¿Qué permite al humilde hacer respetar su personalidad, dignidad y libertad? 
Evidentemente, el derecho natural. Como bien dice Domingo Barbero (17) "en los momentos en que disminuye la comodidad, resurge puntualmente el anhelo de algo más reconfortante que la brutal ley de la fuerza, el hombre perturbado en la tranquila comodidad de la certeza "hecho" positivo, vuelve $\alpha$ buscar "valores" y se dirige a algo cuya búsqueda es más incómoda, pero cuya práctica es más justa".

Desde luego no siempre es procedente recurrir a las leyes esenciales, como no siempre en la vida civil se recurre a los principios constitucionales.

El Derecho Natural como ley-guía es análogo a la estructura de un edificio que puede llenarse en cualquier forma mientras no se afecte su seguridad.

No cabría, pues, invocar el Derecho Natural tratándose de cuestiones secundarias.

Así no es de Derecho Natural que haya o no haya sociedades anónimas, que existan o no mediamerías, que se reglamente 0 no dentro de ciertos límites la propiedad privada, etc. pero en cambio, cuando la ley positiva se opone al Derecho Natural es evidente que éste debe ser preferido. No cabe aceptar en el fuero interno que algo es de derecho natural y en la práctica arrollarlo, pues la ética prohibe la injusticia.

Esto significa que el jurista debe luchar por la reforma de la ley contraria al derecho natural, tratar de reducir o eliminar la aplicación de la norma particular injusta. Interpretar cuando sea posible, la ley en for$m a$ tal que se ajuste al principio moral.

Cuando ya nada de ésto sea posible, cuando se presente la oposición violenta e inconciliable entre la ley divina y la ley humana, entre el derecho natural y el derecho positivo, llega el momento de distinguir si debe tolerarse la ley injusta para evitar peores males o si ha llegado el momento del heroísmo en que debe sacrificarse la vida misma por la fé y por el principio.

La ley positiva no puede ser evadida cuando es justa; ni debe serlo aunque signifique una imposición, sin ser contraria al derecho natural. Menos puede serlo para satisfacer móviles egoístas. Como bien decía Pío XII al Tribunal de la Rota "En los tiempos actuales, cuando se ve en no "pocos debilitado el respeto a la majestad del Derecho y prevalecen so "bre él considerariones de utilidad de intereses, de fuerza y de riqueza, "es necesario que todo abogado católico fiel a su misión, ame $Y$ respete "ante todo la justicia y la verdad".

Hay, sin embargo, leyes de las llamadas "penales" que no deben ser confundidas con el derecho penal, y que son aquellas que establecen la posibilidad de cumplir una obligación ejecutando una prestación susti. tutoria en vez de la principal. No es prohibido, tratóndose de ellas, escoger la alternativa más favorable, siempre que, por supuesto, al elegir esas posibilidades, no se falte a la moral.

Planteada así la situación, las cualidades que ha de tener el hombre de leyes surgen definidas y claras.

(17) Barbero, articulo cilado en la nota 4, p. 49. 
Por supuesto ha de poseer todas aquellas que mencioné al comienzo, las que podríamos llarmar "reglamentarias" pero sólo será completo el día en que goce de todas aquellas que lo acercan a Dios.

Debe poseer por lo mismo una sólida fé, en virtud de la cual actuará siempre teniendo en cuenta la voluntad de su Señor; por razón de la cual lucharớ para descubrir la verdad y practicarla, verdad que es constancia en los propósitos y fidelidad en las promesas. "La verdad os hace libres" ha dicho San Juan (18), la verdad que significa justicia, la verdad que no puede apartarse de la ética, la verdad que permitirá contemplar al Creador.

Debe estar dotado así mismo, de una indeclinable esperanza, esperanza en su redención final, y esperanza también en los hombres, en un mundo no guiado únicamente por el principio bruto de la fuerza y del provecho; esperanza que significa, sin duda, confianza en las leyes $y$ en el valor absoluto de la justicia.

Debe practicar igualmente la caridad, la caridad que hizo conocer tradicionalmente al abogado como el defensor de las viudas y de los huérfanos; la caridad que significa mitigar el dolor de sus semejantes; la caridad que es amor a los demás hombres, como hermanos, como hijos todos de Dios; la caridad y el amor al prójimo que son los únicos que permitirán arrancar la espina del odio y del rencor que tan hondamente va clavada hoy en el corazón de los hombres por la pasión y por el materialismo.

Por tanto evocando a Quintiliano podría decir: "El jurista perfecto "que pretendo describiros no puede llegar a serlo si no es ante todo hom"bre de bien. No exijo de él solpmente el talento eminente de la palabra, "sino, además, todas las cuálidades del alma. Estoy lejos de creer, como "algunos lo han pensado, que hay que dejar a los filósofos lo que con"cieme a la moral y a la sabiduría; pues ante mis ojos el hombre verda"deramente útil a sus conciudadanos, adecuado para la administración de "los negocios públicos y particulares, capaz de regir un Estado por medio "de sus consejos, construírlo por medio de sus leyes y de reformarlo for "sus reglamentos, tal hombre no es otro que el jurista" (19).

(18) Juan, 8, 32.

(19) Jean Appleton. Traité de la Profession d'Arocat. Paris, Librairie Dalloz, 1928, p. 360. 